\title{
ORAL PREDNISOLONE VS. IM CORTICOTROPIN AND HYPSARRHYTHMIA* IN WEST SYNDROME
}

Investigators at University of Columbo, Sri Lanka, studied the efficacy of oral prednisolone (40-60 mg/day) and intramuscular adrenocorticotrophin hormone (40-60 IU synthetic ACTH every other day) for 14 days in improving hypsarrhythmia in children (age 2 mos-2 yrs) with previously untreated West syndrome. Children with tuberous sclerosis were excluded. Eighty of 92 patients (48 randomized to prednisolone and 44 to ACTH) completed the evaluation. Hypsarrhythmia severity score significantly improved with hormonal therapy $(\mathrm{p}<0.01)$; improvement in the prednisolone arm was significantly greater than that in the ACTH arm $(\mathrm{p}<0.01)$. The score system adapted from Kramer et al [1], with a maximum of 16 , employed a 10 -sec segment of the most representative record. Frequent crying, irritability, weight gain, increased appetite, and abdominal distension were more common with prednisolone (but not significantly). Clinical outcome assessment (spasm control) is ongoing. (Wanigasinghe J, Arambepola C, Ranganathan SS, Sumanasena S. The efficacy of moderate-to-high dose oral prednisolone versus low-to-moderate dose intramuscular corticotropin for improvement of hypsarrhythmia in West syndrome: a randomized, single-blind, parallel clinical trial. Pediatr Neurol 2014 Jul;51(1):24-30).

COMMENTARY. Comparative studies of the efficacy of prednisolone and ACTH are difficult to evaluate because of the variations and imbalance of dosages employed. The relative optimum dosages are not known. An editorial suggests that the reported EEG improvement following prednisolone may be at least as good as synthetic ACTH but the superiority of prednisolone is still unclear. Study limitations include brevity of the EEG, especially during sleep, and lack of clinical and developmental outcomes [2]. After ACTH, oral corticosteroids remain the second most commonly used treatment for infantile spasms (with the exception of vigabatrin for patients with tuberous sclerosis).

ACTH vs Predisolone for Spasms Post Vigabatrin Failure. According to the experience at the Hospital for Sick Children, Toronto, Canada, when vigabatrin is ineffective and ACTH unavailable, short-term prednisolone is recommended. While ACTH is more likely to provide short-term relief from spasms, prednisolone is equally effective in the long-term resolution of spasms [3].

Infantile spasms and vitamin B12 deficiency. Investigators in Ankara, Turkey, report two unrelated infants with infantile spasms associated with vitamin B12 deficiency related to maternal nutritional deficiency. After a month of treatment with ACTH, phenobarbital and vitamin B12, both infants' abnormalities resolved. After 3 months, the EEG was normal and ACTH and phenobarbital were discontinued. At 9 months following treatment with vitamin B12, psychomotor developments are improved and the EEG remains normal. For diagnostic clarity, initial treatment with vitamin B12 alone would have been preferred. However, vitamin B12 deficiency should be considered as a cause of infantile spasms in an infant whose mother has severe nutritional deficiency $[4][5]$. 
* Hypsarrhythmia was originally spelled with one ' $r$ ' by the Drs Gibbs who coined the term in 1952 [6]. They wished to emphasize that "the term applied to a specific type of electroencephalographic abnormality" [7], and feared that their definition would be confused by a literal translation of the two ' $r$ ' Greek root, "mountainous arrhythmia" [8]. The one ' $r$ ' spelling was the rule in the 1950s-60s [9]. The two ' $r$ ' spelling became convention in the literature by the mid 1970s [10], with the Gibbs' intended meaning faithfully maintained and accepted for both spellings today.

\section{References.}

1. Kramer U, et al. Neurology. 1997 Jan;48(1):197-203.

2. Mytinger JR, Heyer GL. Pediatr Neurol. 2014 Jul;51(1):13-4.

3. Jones K, et al. J Child Neurol. 2014 Jun 25.

4. Malbora B, et al. Pediatr Neurol. 2014 Jul;51(1):144-6.

5. Erol I, et al. Dev Med Child Neurol. 2007 Oct;49(10):774-6.

6. Gibbs FA, Gibbs EL. Atlas of Electroencephalography. Vol 2. Reading, MA: Addison-Wesley; 1952.

7. Gibbs FA. Infantile Spasms and Hypsarrhythmia or Hypsarhythmia. DMCN. 1965 Jun;7(3):329.

8. Mac Keith R. Dev Med Child Neurol. 1965 Apr;7(2):204.

9. Millichap JG, Bickford RG. JAMA. 1962;182(5):523-527.

10. Google Books: Ngram [Internet]. Incidence of 'hypsarrhythmia' and 'hypsarhythmia'. [cited 8/1/14].

\section{HEADACHE DISORDERS}

\section{LONG-TERM PROGNOSIS OF PEDIATRIC HEADACHES}

Investigators from Dalhousie University, Halifax, Canada, conducted a follow-up telephone interview of patients with a history of headaches diagnosed in 1983. Of 60 patients in the study, follow-up was achieved for 28 (47\%). Over the 30 years since diagnosis, $8(29 \%)$ patients reported a complete resolution. The type of headache varied between migraine and tension-type over the 30-year time interval, only 3 patients maintaining the same headache type at all four time periods between 1983 and 2013. Prescription medication to control the headache was the primary treatment (a triptan) in only one patient, and nonprescription analgesia, self-relaxation and/or hypnosis, and precipitant avoidance were the most commonly used interventions. (Dooley JM, Augustine HF, Brna PM, Digby AM. The prognosis of pediatric headaches-a 30-year follow-up study. Pediatr Neurol 2014 Jul; 51(1):85-7).

COMMENTARY. Headaches persist for up to 30 years in $70 \%$ of children monitored at four 10-year time periods since diagnosis in 1983. Simple analgesia and avoidance of precipitants are the most effective methods of management of pediatric headaches. The goal of treatment is prevention or control, not cure. These results are similar to those obtained in a previous long-term follow-up study of 73 children with migraine; only $23 \%$ were migraine-free at 23 years and more than $50 \%$ continued to have migraine headaches at 50 year follow-up [1]. In children, diet is a factor in the etiology of migraine often difficult to control [2].

\section{References.}

1. Bille BA. Cephalalgia. 1997 Jun;17(4):488-91.

2. Millichap JG, Yee MM. Pediatr Neurol. 2003 Jan;28(1):9-15. 